\title{
"The battle of feeding": Awareness and practices of responsive complementary feeding in Anuradhapura, Sri Lanka - a qualitative study
}

\author{
U W N K Dharmasoma ${ }^{1}$, S S Senevirathne ${ }^{1}$, N Karunamuni ${ }^{1}$, R M M Rathnayaka ${ }^{1}$, P W P W K. \\ Pallewatta $^{1}, *$ T C Agampodi ${ }^{1}$
}

Sri Lanka Journal of Child Health, 2020; 49(1): 08-16

\begin{abstract}
Background: Responsive feeding (RF) is an evidence-based behaviour in complementary feeding. Although included in the infant feeding guidelines of Sri Lanka, it is doubtful whether knowledge and practices entailed to RF is established in the Sri Lankan community.
\end{abstract}

Objectives: To explore the knowledge and practices of RF among mothers having nine month old infants and to explore attitudes of public health midwives (PHMs) towards the concept.

Method: A qualitative study was conducted using in-depth interviews in caregivers of 9 month old infants and focused group discussions in PHMs of Nuwaragam Palatha Central area in Anuradhapura district. Interviews were tape recorded, transcribed and thematic analysis performed.

Results: None of the mothers effectively practised the full concept of RF. Only a few mothers have prepared a separate feeding place. Although signals of hunger and satiety were identified, most mothers did not use them in an appropriate manner in feeding. Letting the child watch television and taking the child round the garden were common suboptimal practices. Mothers stated the difficulty in introducing new food to their children indicating lack of reciprocity between them and children. The public health midwives also had poor understanding on total concept of RF.

Conclusions: PHMs and mothers having nine month old infants have poor understanding and practices on the concept of RF.

\footnotetext{
${ }^{1}$ Department of Community Medicine, Faculty of

Medicine and Allied Sciences, Rajarata University of Sri Lanka.

*Correspondence: thilinichanchala@yahoo.com

https://orcid.org/0000-0003-0991-6237

(Received on 20 April 2019: Accepted after revision on 24 May 2019)

The authors declare that there are no conflicts of interest

Personal funding was used for the project.

Open Access Article published under the
}

Commons Attribution CC-BY (c) (i) License
DOI: http://dx.doi.org/10.4038/sljch.v49i1.8891

(Key words: Feeding, responsive feeding, nutrition, behaviour, complementary feeding, Sri Lanka)

\section{Background}

Behaviour of caregivers is important to combat malnutrition among infants and young children. Many studies throughout the world ${ }^{1}$, including Sri Lanka $^{2}$, indicate that it is not only knowledge but behaviour that matters in child nutrition. Responsive feeding (RF) is an evidence-based behaviour in nutrition promotion ${ }^{3,4}$. It consists of four components: pro-active preparation, identifying child's signals of hunger and satiety, caregiver promptly acting on child's signals in a warm, age appropriate manner, and the child predicting a favourable response from caregiver ${ }^{3}$. Parent responsiveness occurs as a supportive routine whereby the child learns to expect responses that are predictable and supportive ${ }^{3}$. Distractions are minimized during feeding ${ }^{5}$. Mealtime structure and RF are associated with more desirable eating behaviour ${ }^{6}$ and healthier dietary patterns ${ }^{7,8}$, greater weight gain and more self-feeding among infants ${ }^{9}$. In Sri Lanka, RF is incorporated into National Infant Feeding Guidelines $^{5}$. Public Health Midwives' (PHMs) awareness and quality of services are crucial for adequate skill development. Recognizing these problems is essential to evaluate and implement future strategies on nutrition behaviour.

\section{Objectives}

To explore the knowledge and practices of RF among mothers having nine month old infants and to explore attitudes of PHMs towards the concept.

\section{Method \\ Study design: A qualitative design, including in- depth interviews with mothers (caregivers) and focus grouped discussions with PHMs, was used to achieve the study objectives.}

Study setting: Present study was conducted in Nuwaragampalatha Central (NPC) area, the largest Medical Officer of Health (MOH) area in Anuradhapura district, North Central Province of Sri Lanka. In Sri Lankan public health hierarchy, a district is divided into health administrative $\mathrm{MOH}$ areas, where the $\mathrm{MOH}$-a medical doctor- is in 
charge. Each $\mathrm{MOH}$ area is divided into PHM areas. PHMs are the grass root level maternal and child health care service providers and the study population is easily accessible via them. They are involved in promoting breastfeeding, complementary feeding and other maternal and child health activities and understand the usual feeding behaviour and habits of the mothers in their field practice area. The MOH area NPC has 23 PHMs in 28 PHM areas with a total population of 61,223 . The area consists of semi-urban to rural populations. The coverage of immunization services in the district is $99-100 \%$.

Study participants: Study participants were of two types. We recruited mothers of nine month old infants residing in NPC MOH area in the Anuradhapura district. Particular group of mothers was selected as they are expected to practise complementary feeding since six months of age of infant and have received knowledge and developed skills through information given by the public health staff. At nine months the child starts feeding on his own. Additionally it is convenient to select mothers attending for the nine months vaccination sessions. PHMs of the area were selected as they are the grass root level service providers and the ideal informants to interview about the feeding practices in their field.

Sampling and recruitment of participants: Mothers were selected from randomly selected three immunization clinics conducted in the $\mathrm{MOH}$ area. Initially three mothers were selected from each clinic and we continued recruitment until data saturation. If the primary caregiver was not the mother (in case mother was employed) or if someone else is doing the feeding, those mothers were excluded from the interviews. Mothers were selected to represent different socio-demographic backgrounds. The PHMs were gathered on a day of in-service training at the $\mathrm{MOH}$ office to conduct focus group discussions. Full information about the study was given and the procedure was explained by the investigators and informed written consent for the study was obtained.

Data collection instruments: An interviewer guide (Table 1) was developed according to standard recommendations and guidelines ${ }^{12,13}$. The guide was developed in Sinhala as the in depth interviews were conducted in Sinhala. Probing questions were also developed to explore the areas of interest regarding RF. The guide consisted of open-ended questions regarding the 4 areas of RF.

Table1: Interviewer guide for in-depth interviews of mothers

\begin{tabular}{|c|c|c|}
\hline Main component of $\mathrm{RF}$ & Main questions & Probing questions \\
\hline Pro-active preparation & $\begin{array}{l}\text { Can you describe the place or places } \\
\text { where you usually feed the baby? } \\
\text { When do you usually feed the child? } \\
\text { At what times of the day? }\end{array}$ & $\begin{array}{l}\text { Do you feed the child in the same place } \\
\text { in home or in different places every } \\
\text { day? } \\
\text { Can you describe whether the child } \\
\text { likes to have food in that place? } \\
\text { How do you make the place attractive } \\
\text { to the child? }\end{array}$ \\
\hline Identifying child's signals & $\begin{array}{l}\text { How would you recognize that your } \\
\text { child is hungry? } \\
\text { How would you know that your child } \\
\text { is satisfied? }\end{array}$ & \\
\hline $\begin{array}{l}\text { Caregiver acts promptly, } \\
\text { warmly and age appropriately } \\
\text { to child's signals }\end{array}$ & $\begin{array}{l}\text { How do you act when you know that } \\
\text { the child is hungry? } \\
\text { Can you describe the type of food, } \\
\text { amount and way you prepare it? } \\
\text { How do you usually act while feeding } \\
\text { the child? }\end{array}$ & $\begin{array}{l}\text { How long will it take to prepare the } \\
\text { food when you know he is hungry? } \\
\text { Are you able to feed the child as soon } \\
\text { as you know he is hungry? How do you } \\
\text { do this? } \\
\text { Do you talk with the child? What are } \\
\text { the things that you say to the child? } \\
\text { Do you show him love and affection? } \\
\text { How do you react when the child is } \\
\text { trying to have food on his own? } \\
\text { Do you have to engage in other work } \\
\text { while the child is feeding? } \\
\text { What sort of things distracts you from } \\
\text { paying attention to the child? }\end{array}$ \\
\hline $\begin{array}{l}\text { Child predicts a favourable } \\
\text { response from mother }\end{array}$ & $\begin{array}{l}\text { What about the relationship between } \\
\text { you and your child? }\end{array}$ & $\begin{array}{l}\text { "Do you feel that your child is easy to } \\
\text { handle"? } \\
\text { How does the child react when you } \\
\text { make suggestions like "let's wash } \\
\text { hands", "let's eat"? }\end{array}$ \\
\hline
\end{tabular}


The guides for focus group discussions (Table 2) were also designed according to standards ${ }^{12,13}$ and were focused on the knowledge of PHMs on RF and their perception on mothers' awareness and practice of RF in their field. These were also developed in Sinhala as the majority of target population and the interviewers are Sinhalese and the discussions were carried out in Sinhala. Data collection instruments were pilot tested.

Table 2: The guide for focus group discussions with PHMS

\begin{tabular}{|c|c|}
\hline Main theme & Questions \\
\hline $\begin{array}{l}\text { Knowledge of RF among PHMs and } \\
\text { perceptions in the field }\end{array}$ & $\begin{array}{l}\text { What do you understand by RF? } \\
\text { What is your idea about knowledge in mothers in your area? }\end{array}$ \\
\hline Pro-active preparation & $\begin{array}{l}\text { According to your knowledge how should the place where } \\
\text { children have their food be prepared? } \\
\text { Can you describe the place or places where mothers in your } \\
\text { area feed their children? } \\
\text { Do they have a separate place for feeding or do they use } \\
\text { different places? } \\
\text { Have they prepared it in an attractive way? }\end{array}$ \\
\hline Identifying child's signals & $\begin{array}{l}\text { How do mothers in your area know that their children are } \\
\text { hungry? When do the mothers stop feeding at each meal? } \\
\text { How do the mothers in your area know that their children are } \\
\text { satisfied? }\end{array}$ \\
\hline $\begin{array}{l}\text { Caregiver act promptly, warmly and age } \\
\text { appropriately to child's signals. }\end{array}$ & $\begin{array}{l}\text { According to your view, is it necessary that a mother be } \\
\text { prepared to feed the child when he is hungry or can she } \\
\text { prepare food when they feel hungry? } \\
\text { What is your idea about the knowledge of mothers on } \\
\text { changing and serving food according to their children's ages? } \\
\text { What can you say about feeding the child with love and care? } \\
\text { Can you describe what mothers in your area do when feeding } \\
\text { the child? } \\
\text { Do they stay near the child, talk with love and affection or do } \\
\text { they engage in other work? } \\
\text { What is your idea about the incidents which draws } \\
\text { child's/mother's attention away while the child is eating? } \\
\text { How do the mothers help their children to self-feed? }\end{array}$ \\
\hline $\begin{array}{l}\text { Child predicts a favourable response from } \\
\text { mother }\end{array}$ & $\begin{array}{l}\text { Can you describe the connection between the mother and the } \\
\text { children in your area while they feed their children? }\end{array}$ \\
\hline
\end{tabular}

RF: Responsive feeding, PHMs: Public health midwives

Training of data collectors: Data collectors were pre-intern medical officers of the Department of Community Medicine, Faculty of Medicine and Allied Sciences, Rajarata University of Sri Lanka. They were trained for qualitative interview techniques and for data collection and storage using demonstrations by experts in the field according to standard guidelines ${ }^{12,13}$.

Data collection procedure: A convenient time and place for the participants were selected within the clinic premises to conduct interviews. The in depth interviews were conducted before vaccination of the child as the mother would have been impatient and frustrated with a crying child following vaccination and would fail the interview as well. The interviews were tape recorded with permission. A note-taker took down notes. Each interview lasted about twenty to thirty minutes and at the end of the session, a summary of the recorded data was presented to the participants for respondent validation. The notes taken during the interview were expanded immediately after the interview. Recorded data was transcribed within the first few days of the interview. Transcription, organization and storage of data were done according to the FHI guidelines $^{12}$. The focus group discussions were conducted with PHMs at the MOH office on an inservice training session which was a convenient day and place for the participants to attend. Full information about the study was given and the procedure was explained by the principal investigator. Each focus group had 8-12 PHMs, was mediated by a moderator and was documented by a note taker. Interviews were tape recorded with the consent of the participants and data was expanded and transcribed soon after the interview. Data collection was continued until data saturation was achieved.

Analysis of data: An inductive thematic analysis was performed. 
Ethical and administrative considerations: Ethical clearance for the study was obtained from Ethics Review Committee, Faculty of Medicine and Allied Sciences, Rajarata University of Sri Lanka. Participants were provided with a full explanation about the purpose, general content and the objectives of the study and informed written consent was obtained from each participant. Privacy and confidentiality of data were protected.

\section{Results}

Ten mothers and twenty PHMs participated in the study.

\section{Maternal knowledge about RF}

Some mothers knew that they should feed in a specific place and that they should feed the child with love and care. Most mothers fed their children with age appropriate food. However, none of them had an idea of the full concept of RF nor its scientific basis or importance. PHMs had different opinions on the knowledge of mothers.

"Some mothers practise RF but some do not, even when they have the knowledge and younger mothers do not have the knowledge"- A PHM NPC In contrast, another PHM's idea was that "75\% of teaching on RF is easily grasped by the mothers".

\section{Pro-active preparation}

Place of feeding: Most of the mothers did not have a clue about the need of a specific place to feed the child. They fed the child wandering inside and outside the house while showing pictures, trees, animals and the surroundings. Some had a separate place for feeding the child but did not stick to that place. "Corner of the bed", "a wooden cart of the child with toys" or "a mat in the living room with toys" were some examples for specific places. But none of the mother-infants pairs intended to use these places as specific for feeding and mothers had to change the place from time to time to get their child to eat something. Even the above places were neither specially designed nor free of distractions. "I feed my child sitting on a chair in the morning and the lunch is given wandering around the garden showing cats, dogs, birds by the grandmother and in the evening I feed showing insects on the wall. It is hard to feed in one place" (Mother D)

The PHMs also had the same observations about feeding the infants in their field. Some mothers had fed the child just in front of the television.

"Now some children do not eat when inside the house, wandering around the garden is a must". $-A$ PHM NPC

Separate, attractive utensils for feeding: Mothers had well perceived ideas of separate utensils for feeding the child and every participant had been using separate cups and plates with bright colours to feed their child.
According to PHM, most of the mothers had a separate plate for the child, but some do not care, some had economic problems and many other barriers.

"Although very poor, all have a separate plate for the child" -PHM NPC

Some of them had deviated practices

"Some mothers get 2-3 plastic plates and change every day"-PHM NPC

They also mentioned other good practices.

"Some mothers do not like the child throwing food on the ground and messing the place, so they offer food with a plantain leaf or a paper underneath the plate". -PHM NPC

Time of feeding: Although mothers had the ability to identify the hunger cues of their child, very few fed their child according to hunger cues. Most of the mothers had given food according to time of the day. They were able to directly tell the time of feeding because they had fed their child according to the clock. When the routine of feeding was asked they said.

"I feed my child 8.00 a.m. to 8.30 a.m. in the morning, 1.00 p.m. to 1.30 p.m. at noon and at 7.00 p.m. in the evening". (Mother E)

Mothers did not wait until their child gets hungry but fed them routinely around the clock, thinking that it must be done to gain adequate weight and development of the child. Only one or two mothers had tried feeding their child following hunger cues. Some mothers practised force feeding with or without signs of hunger.

PHMs agreed to the same idea about time of feeding.

"Some mothers say that there is no time the child is hungry and feed them around the clock". PHMNPC

According to some PHMs, missing the early morning meal was common. They feel that the rural women are lazy, wake up late and feed the breakfast around $10.00 \mathrm{am}$.

\section{Identification of hunger and satiety cues}

Every mother, with or without understanding the concept of RF could identify their child's hunger and satiety signs.

"I can easily identify hunger and satiety signs of the baby" (Mother A)

Mothers identified "crying" as the most common hunger sign and other signs identified were getting irritable and panic, smiling at the sight of food, trying to reach for food or breast of mother, dry mouth, yawning and lack of energy, calling mom, moaning etc. which depicts the variety of the hunger cues of young children. A few satiety signs identified among children in the study were smiling, looking away refusing food, nausea, putting food out of the mouth, and tightly closing the mouth, hitting the plate or mother's hand and spilling out food. 
Caregiver action on child's hunger and satiety

Most mothers had been able provide the child food within 1-2 minutes.

"I always keep the food pre prepared and can start feeding the baby within 1-2 minutes after identifying hunger. "(Mother A)

However, two mothers took about 10-20 minutes to provide food to the child.

"I get about $10 \mathrm{~min}$ to prepare food after identifying hunger" (Mother D)

"I often give fruits to the child when hunger is identified as I need about $20 \mathrm{~min}$ to prepare rice-a main meal" (Mother $\mathrm{H}$ )

However PHMs have a different idea on this. According to them only a small fraction of mothers in the field try to respond to child's hunger cues immediately.

"When child asks for rice, mothers do their own work and make the child wait". PHM-NPC

"Some mothers give something just to alleviate the hunger like biscuits, "samaposha" (an instant native cereal diet), instant noodles or milk but not a main meal." PHM-NPC

"Mothers ignore their child's hunger and do other work such as carrying the elder child to tuition classes or engaging in paddy field work". PHMNPC

It was observed by the PHMs that the weight gain of the children in the farming community usually decline in the cultivating seasons.

\section{Conversation built between child and mother}

Mothers had talked about the food child is eating and they described the food items.

"Let's eat yoghurt" (Mother J)

"When I am feeding my child, I talk to him about food on the plate with love and affection." (Mother I)

"Both me and my husband like to feed the baby while talking and I teach new words to the child" (Mother E)

Some of them had mixed practices of both responsive and non-responsive feeding.

"While feeding my child, I play with child, show toys and also introduce food in the plate."(Mother $\mathrm{B}$ and $\mathrm{F}$ )

"I talk with my baby while feeding, showing surroundings and also food in the plate."(Mother C)

But some mothers' conversation was just a phrase like

"Food is delicious, isn't it my dear?"

Few mothers had the perception that talking is a way of feeding by distracting the child.

"I talk with the child when feeding; showing toys or else get the TV on". (Mother G)

PHMs of the area also agree with these results.

\section{Age appropriate food}

Most of the mothers in the study had not given foods which are totally appropriate to their infant's age. They had given the 3 main meals consisting of rice with vegetables, green leaves, egg, sea food, etc. and fruits and biscuits/buns as snacks in between. Also "Thriposha" (an instant native cereal diet) was included in their daily diet as a snack and some infants were given the usual family meal.

"For the breakfast I feed the child with 'Samaposha/Thriposha' with added sugar, for lunch overcooked rice with dhal, pepper/lime juice/coconut milk added with vegetables like carrot, potatoes, green leaves. And for the dinner, rice with different ingredients. I give my child oranges, apples, papaw about once a week." (Mother E)

PHMs of the area did not have the same idea about giving age appropriate food to infants in their fields.

"Some mothers continue to give only the smashed rice to their children as they gulp it quickly without any trouble" PHM NPC

\section{Food diversity}

During infancy mothers had the behaviour of maintaining the diversity of the meal.

"We use to add dhal, green leaves, pumpkin, fish etc." (Mother A)

Mothers also had the habit of including different types of green leaves cheap and freely available in their gardens.

Using fish, meat and eggs was less. However, many mothers used to add dried sprats (powdered) to the meal.

PHMs had the opinion that the diversity of food changes with the season. According to them, at times when pumpkin and corn harvest is produced in farmlands the children gain weight.

However it was mentioned that after one year the children get used to have their preferences for food and the diversity of the meal is restricted.

\section{Use of sweet and salty foods}

Mothers knew very well that adding salt and sugar during infancy is not permitted.

However suboptimal practices were observed in the field.

"Some mothers have the habit of preparing an instant noodles as soon as the child shows hunger. Some give biscuits, formula milk and "samaposha" (a prepared cereal).” PHM

\section{Distractions}

The place of feeding was full of distractions and none of the mothers mentioned about a peaceful place for offering meals. It was the television, radio in one or two homes and elder siblings playing everywhere. Mothers had never thought the distractions as a problem and it was more like that 
the mothers have developed the habit of using these distractions to feed their child.

"My elder son is playing while infant is fed and he shows toys and the infant likes to eat while looking at them." (Mother A)

"I usually feed the child outside the house. It's easier as I can feed by showing different things." (Mother D)

According to the PHMs multiple distractions such as trees, pets, birds, television, are used as a prominent behaviour in feeding infants.

\section{Forced feeding}

Forced feeding was observed by the PHMs.

"Some mothers force feed. The children are never happy. They do not gain weight."

"Some mothers keep the spoon in the mouth until the child swallows. Sometimes they try to fill the mouth while the child is falling asleep"'-PHM NPC.

\section{Development of understanding between mother and child}

According to a PHM NPC, "There is good motherchild bond. The understanding of the child is more in mothers who spend more time with the child"

But, all of them agreed that, "feeding is a battle and full of complaints", which depicts the after effect of non-responsive feeding to children and gives the whole picture at once.

\section{Attitude of PHMs about the awareness and barriers of $R \boldsymbol{F}$}

Attitude about awareness: As PHMs also did not have correct understanding about the full concept of RE, their opinions were controversial.

"Seventy five percent of teaching on RF is quickly caught by the mothers" according to a PHM NPC.

In contrast one other PHM NPC declared that "Young mothers have minimum awareness and some do not practise even if they know the concept"

There were socio-demographic disparities identified in providing and grasping the knowledge. Urban mothers were more educated and practical, having access to various sources of knowledge and grasped the concepts given by the staff more successfully, but had less time to participate in the sessions. Unlike them, rural mothers, mostly housewives, were enthusiastically participating but could not understand the concepts quickly as they had lower education levels.

"There is less knowledge in mothers residing in rural areas due to less education level, but participation is high and they also have time to try new food. There is less participation to education sessions by urban mothers but the knowledge and understanding is comparatively higher." -PHM NPC
Barriers for optimal practice: According to PHMs socioeconomic problems had been the main barriers to optimal feeding practice.

"Some do not have even a place to sleep, so how can they have a separate place to feed the child?" PHM NPC

"Some do not care, some have economic problems and some do not try to practise though they have the ability." -PHM NPC

Ignorance of mothers involved in the battle of living doing farming or office work had an equal negative impact on their children. Mothers did not have enough time to spend on feeding and the caregivers at home did not know about practices of RF. Also, employed mothers could not participate in teaching sessions done by PHMs.

"Although we promote $R F$, only the housewives are practising these, but the employed mothers are not practising and also the caretakers do not practise”- PHM NPC

"We cannot achieve our goals of $R F$ as some caregivers other than parents are not practising $R F$. As the mother is going for the job, she is not available to grab our teaching. This is a common problem to the field officers and hospital staff"PHM NPC

\section{Discussion}

This study explores the attitude, awareness and maternal practices of RF, a less studied area in infant feeding practices. Knowledge and perception of the primary health care workers (PHMs) were also embedded in the study. This is one of the very few studies done to evaluate RF which was implemented under a government public health programme ${ }^{12,13}$. The main finding of this study was that neither mothers nor PHMs knew the concept of RF as a whole. PHMs knew that infants should be fed in one place with warmth and love. The mothers lacked both knowledge and skills on RF. Although mothers knew their child's signs of hunger which varied widely as in other studies ${ }^{14}$, they did not promptly act on these signs. Instead, they had a convenient time schedule to feed the child and sometimes tried force feeding. Neither mothers nor PHMs had the idea of developing the bond between mother and child ${ }^{15,16}$. The main reason for this could be insufficiency in delivering the concept of RF to public health personnel at central level. In Sri Lanka, usually the public health concepts and training are mediated by the Ministry of Health up to the peripheries. Although RF is in the National Infant Feeding Guidelines, a holistic approach is missing.

Mothers and health officers do not know the rationale and scientific basis of RF. When planning behavioural change interventions, it is important that we clearly communicate the expected change and reason/s for changing the behaviour to the 
public $^{3}$. As women in Sri Lanka possess high literacy ${ }^{17}$ and health literacy, it is easy to include the scientific basis of a concept in public health intervention $^{18}$. It has been successfully implemented in promoting Early Childhood Care and Development (ECCD) in the country ${ }^{19}$.

Many barriers for cultivation of proper feeding practices are identified by the PHMs. Other studies also suggest evaluating barriers of optimal feeding such as maternal nutrition, mental health status, household decision-making, social conditions, local customs and time allocation ${ }^{3,20}$. The interventions may require not only improving health aspects but inter-sectoral coordination to upgrade standards of living ${ }^{21}$.

Mothers who were more responsive during feeding tended to have comparatively higher educational levels ${ }^{22}$. They may have a greater understanding and concern of child development or may possess higher economic levels. However, if mothers become too busy with their occupation, practice of $\mathrm{RF}$ is influenced negatively. Findings of the current study are consistent with past studies showing that infants of mothers who were unmarried, had lower income or lower education, were more likely to have suboptimal feeding behaviour ${ }^{7,23}$.

This study concluded that several sociodemographic factors determine the success of the practice in addition to education provided on topic ${ }^{23}$. Instead of using only health education which is not very effective ${ }^{9}$, stronger strategies of giving information ${ }^{8,25}$ and using different methods might help in behavioural changes ${ }^{8,26}$. This study depicts that the proportion of knowledge grasped by individuals vary. Thus, health care professionals need to address each one separately ${ }^{28}$. This suggests the need for identification of bottlenecks in routine healthcare delivery and implementing suitable strategies focusing on behavioural change. The model of teaching and practising RF must be implemented across multiple sectors of healthcare, public health, and community organizations serving families and be feasible in all cultures, incomes, and languages ${ }^{29}$. The suggested novel modes of nutrition education and strategies focusing on behavioural change can be experimented in similar study settings. Also, there are emerging scales validated to measure the outcome which can be used in future studies.

Several limitations were identified. Although PHMs mentioned socio-economic disparities, interviewing mothers did not reveal those and the investigators did not collect such information. Feeding patterns and behaviours could be quite different among different ethnic groups. In the present study only Sinhalese mothers were interviewed due to time and human resource constraints. Evidence generated by this study would have been stronger if we used video-taped or real time observation of feeding children at households despite the challenge of data analysis. This has been already suggested by other researchers ${ }^{20,30}$. The concept of child lead complementary feeding was not assessed during this study as it was not established nor promoted in the National Programme for Infant and Young Child Feeding in Sri Lanka. However, recently, the concept has gained much attention globally and specifically inquiring health staff and caregivers on the aspects would have added more value to this study.

Underlying socio-economic factors should be considered in implementation of behavioural change to improve child nutrition. The need for more effective strategies other than just education is well depicted. The strategies should be more practical, feasible, and accessible and should cover all possible caregivers including fathers, grandmothers, grandfathers and paid caregivers. Strengthening RF delivery at National level by incorporating all four components as well as the scientific basis might have propitious effects on combating childhood malnutrition in Sri Lanka.

\section{Conclusions}

PHMs and mothers having nine month old infants have poor understanding and practices on the concept of RF.

\section{References}

1. Black MM, Hurley KM. Responsive feeding: Strategies to promote healthy mealtime interactions. Nestle Nutrition Institute Workshop Series 2017; 87:15365.

https://doi.org/10.1159/000448965

PMid: 28315896

2. Hetherington MM. Understanding infant eating behaviour-Lessons learned from observation. Physiology and Behavior 2017; 176: 117-24.

https://doi.org/10.1016/j.physbeh.2017.01. 022

PMid: 28089707

3. Birch LL. Learning to eat: Behavioral and psychological aspects. Nestle Nutrition Institute Workshop Series 2016; 85:12534.

https://doi.org/10.1159/000439503

PMid: 27088340

4. Agampodi TC. Responsive feeding: the missing link in child malnutrition in Sri 
Lanka. Sri Lanka Journal of Child Health 2014; 43(1):53-4.

https://doi.org/10.4038/sljch.v43i1.6662

5. Infant and Young Child Feeding Guidelines for Sri Lanka 2000. Available from:

https://medicine.kln.ac.lk/depts/publicheal th/Fixed_Learning/Nutrition/Guidelines $\%$ 20 on $\% 20$ Infant $\% 20$ and $\% 20$ Young $\% 20 \mathrm{Ch}$ ild $\% 20$ Feeding.pdf

6. Hodges EA, Johnson SL, Hughes SO, Hopkinson JM, Butte NF, Fisher JO. Development of the responsiveness to child feeding cues scale. Appetite 2013; 65:210-9.

https://doi.org/10.1016/j.appet.2013.02.01 0

PMid: 23419965 PMCid: PMC3995412

7. Finnane JM, Jansen E, Mallan KM, Daniels LA. Mealtime structure and responsive feeding practices are associated with less food fussiness and more food enjoyment in children. Journal of Nutrition Education and Behaviour 2017; 49(1):11-8.

https://doi.org/10.1016/j.jneb.2016.08.007

PMid: 27707544

8. Hohman EE, Paul IM, Birch LL, Savage JS. INSIGHT responsive parenting intervention is associated with healthier patterns of dietary exposures in infants. Obesity 2017; 25(1):185-91.

https://doi.org/10.1002/oby.21705

PMid: 28008749 PMCid: PMC5189916

9. Fewtrell M, Haschke F, Prescott. Complementary feeding: Taste, eating behaviour and later health. Nestle Nutrition Institute Workshop Series 2016; 85:145-54.

10. Aboud FE, Moore AC, Akhter S. Effectiveness of a community-based responsive feeding programme in rural Bangladesh: a cluster randomized field trial. Maternal and Child Nutrition 2008; 4(4):275-86.

https://doi.org/10.1111/j.17408709.2008.0 0146.x

PMid: 18811792

11. Agampodi TC, Agampodi SB, Chathurani U. Infant feeding behaviours in Nuwaragam-Palatha-Central (NPC) Medical Officer of Health (MOH) area; a qualitative study. 3rd Annual Academic
Sessions of the Anuradhapura Clinical Society, Anuradhapura, Sri Lanka, 2012. https://doi.org/10.4038/amj.v6i1.5767

12. Qualitative Research Methods - A Data Collector's Field Guide. Available from: https:/www.fhi360.org/sites/default/files/ media/documents/Qualitative\%20Researc h\%20Methods $\% 20 \% 20 \mathrm{~A} \% 20$ Data $\% 20 \mathrm{Co}$ llector's $\% 20$ Field $\% 20$ Guide.pdf

13. Kvale S, Brinkmann S. Interviews. Learning the crafts of Qualitative Research Interviewing. $2^{\text {nd }}$ Edition. Sage Publications 2014

14. Bhandari N, Mazumder S, Bahl R, Martines J, Black RE, Bhan MK et al. An educational intervention to promote appropriate complementary feeding practices and physical growth in infants and young children in rural Haryana, India. Journal of Nutrition 2004; 134(9): 2342-8.

https://doi.org/10.1093/jn/134.9.2342

PMid: 15333726

15. Penny ME, Creed-Kanashiro HM, Robert RC, Narro MR, Caulfield LE, Black RE. Effectiveness of an educational intervention delivered through the health services to improve nutrition in young children: a cluster-randomised controlled trial. Lancet 2005; 365(9474): 1863-72. https://doi.org/10.1016/S01406736(05)664 26-4

16. McNally J, Hugh-Jones S, Caton S, Vereijken $\mathrm{C}$, Weenen $\mathrm{H}$, Hetherington $\mathrm{M}$. Communicating hunger and satiation in the first 2 years of life: a systematic review. Maternal and Child Nutrition 2016; 12(2):205-28.

https://doi.org/10.1111/mcn.12230

PMid: 26620159 PMCid: PMC4991302

17. Tovar A, Hennessy E, Must A, Hughes SO, Gute DM, Sliwa S, et al. Feeding styles and evening family meals among recent immigrants. International Journal of Behavioral Nutrition and Physical Activity 2013; 10:84.

https://doi.org/10.1186/1479-5868-10-84

PMid: 23803223 PMCid: PMC3708789

18. Bentley ME, Dickin KL, Mebrahtu S, Kayode B, Oni GA, Verzosa CC, et al. Development of a nutritionally adequate and culturally appropriate weaning food in 
Kwara state, Nigeria: an interdisciplinary approach. Social Science and Medicine 1991; 33(10):1103-11.

https://doi.org/10.1016/02779536(91)9022 6-3

19. LeVine RA. Human parental care: universal goals, cultural strategies, individual behavior. New Directions for Child and Adolescent Development 1988; 40: $3-12$.

https://doi.org/10.1002/cd.23219884003

20. Briscoe C, Aboud F. Behaviour change communication targeting four health behaviours in developing countries: A review of change techniques. Social Science and Medicine 2012; 75(4): 61221.

https://doi.org/10.1016/j.socscimed.2012.0 3.016

PMid: 22541798

21. Literacy rate - adult female (\% of females ages 15 and above) in Sri Lanka [Internet]. [cited 2017 Aug 30]. Available from: https://tradingeconomics.com/srilanka/liter acy-rate-adult-female-percent-of-femalesages-15-and-above-wb-data.html

22. Statistics | Sri Lanka | UNICEF [Internet]. [cited 2017 Aug 30]. Available from: https://www.unicef.org/infobycountry/sri lanka_statistics.html

23. The National Policy on Early Childhood Care and Development - Asia-Pacific Regional Network for Early Childhood. Available from:

http://www.arnec.net/statement/thenational-policy-on-early-childhood-careand-development-eccd/

24. Allen KL, Gibson LY, McLean NJ, Davis EA, Byrne SM, Argenti M, et al. Problem eating behaviours related to social factors and body weight in preschool children. International Journal of Behavioral Nutrition and Physical Activity 2011; 100(1):1-10.

25. Engle P, Pelto G. Responsive feeding: implications for policy and program implementation. Journal of Nutrition 2011;141:508-11.

https://doi.org/10.3945/jn.110.130039

PMid: 21270361 PMCid: PMC3040908

26. Gibson RS, Abebe Y, Hambidge KM, Arbide I, Teshome A, Stoecker BJ. Inadequate feeding practices and impaired growth among children from subsistence farming households in Sidama, Southern Ethiopia. Maternal and Child Nutrition 2009; 5(3):260-75.

https://doi.org/10.1111/j.17408709.2008.0 0179.x

PMid: 20572929

27. DiSantis KI, Hodges EA, Johnson SL, Fisher JO. The role of responsive feeding in overweight during infancy and toddlerhood: a systematic review. International Journal of Obesity 2011; 35(4):480-92.

https://doi.org/10.1038/ijo.2011.3

PMid: 21427696

28. Kulwa KB, Verstraeten R, Bouckaert KP, Mamiro PS, Kolsteren PW, Lachat C. Effectiveness of a nutrition education package in improving feeding practices, dietary adequacy and growth of infants and young children in rural Tanzania: rationale, design and methods of a cluster randomised trial. BMC Public Health 2014; 14(1):1077.

https://doi.org/10.1186/1471-2458-14-

1077

PMid: 25318980 PMCid: PMC4216379

29. Majamanda J, Maureen D, Munkhondia TM, Carrier J. The effectiveness of community-based nutrition education on the nutrition status of under-five children in developing countries. A systematic review. Malawi Medical Journal 2014; 26(4):115-8.

30. White S, Schmidt W, Sahanggamu D, Fatmaningrum D, van Liere M, Curtis V. Can gossip change nutrition behaviour? Results of a mass media and communitybased intervention trial in East Java, Indonesia. Tropical Medicine and International Health 2016; 21(3):348-64. https://doi.org/10.1111/tmi.12660

PMid: 26701153 